\title{
Global patterns in overweight among children and mothers in less developed countries
}

\author{
Jennifer Van Hook ${ }^{1, *}$, Claire E Altman ${ }^{1}$ and Kelly S Balistreri ${ }^{2}$ \\ 'Department of Sociology, The Pennsylvania State University, 601 Oswald Tower, University Park, PA 16802, \\ USA: ${ }^{2}$ Department of Sociology, Bowling Green State University, Bowling Green, OH, USA
}

Submitted 6 December 2011: Final revision received 25 January 2012: Accepted 13 March 2012: First published online 14 May 2012

\begin{abstract}
Objective: Past research has identified increases in national income and urbanization as key drivers of the global obesity epidemic. That work further identified educational attainment and urban residence as important moderators of the effects of national income. However, such work has tended to assume that children and adults respond in the same way to these factors. In the present paper, we evaluate how the socio-economic and country-level factors associated with obesity differ between children and their mothers.

Design: We modelled the associations between maternal education, country-level income and urban residence with mother's and children's weight status.

Setting: We analysed ninety-five nationally representative health and nutrition surveys conducted between 1990 and 2008 from thirty-three less developed countries.

Subjects: Our sample included children aged 2-4 years ( $n$ 253442) and their mothers ( $n$ 228 655).

Results: Consistent with prior research, we found that mothers' risk of overweight was positively associated with economic development, urban residence and maternal education. Additionally, economic development was associated with steeper increases in mothers' risk of overweight among those with low ( $v$. high) levels of education and among those living in rural ( $v$. urban) areas. However, these associations were different for children. Child overweight was not associated with maternal education and urban residence, and negatively associated with national income.

Conclusions: We speculate that the distinctive patterns for children may arise from conditions in low- and middle-income developing countries that increase the risk of child underweight and poor nutrition.
\end{abstract}

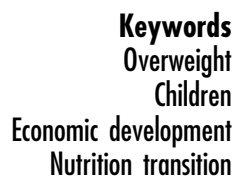

Although the prevalence of obesity and overweight is highest in wealthy countries like the USA, it is increasing rapidly in several less developed countries among both adults and children ${ }^{(1)}$. Worldwide obesity prevalence has doubled since $1980^{(2)}$ and the obesity rate among women in some middle-income countries like Mexico and Egypt is about as high as in the USA ${ }^{(1)}$. Among pre-school children (aged 0-5 years) in less developed countries, the prevalence of overweight and obesity $\dagger$ has increased in nearly every country for which data are available ${ }^{(3)}$. One group estimated that it increased worldwide from $3.7 \%$ in 1990 to $6 \cdot 1 \%$ in $2010^{(4)}$. As underscored in the recent UN Report of the Secretary-General ${ }^{(5)}$, the troubling increase in obesity in less developed countries will add

$\uparrow$ Overweight in the referenced study is defined as the proportion of children of pre-school age greater than $2 \mathrm{sD}$ from the WHO growth standard median; obesity as greater than 3 sD from the median. to health-care costs for societies that are already burdened with poverty and the challenges of managing infectious disease.

In a recently published series of articles in The Lancet, the editors emphasized that the increasing weight of people worldwide is the result of a normal response by normal people to an abnormal environment' ${ }^{(6)}$. This perspective is most evident in the widely cited nutrition transition theory ${ }^{(7)}$, which relates economic development and urbanization to shifts in food consumption and physical activity patterns, and these to increases in obesity. Consistent with this view, past research has identified increases in national income and urbanization as key drivers of the global obesity epidemic ${ }^{(1)}$. A major limitation of such work, however, is the assumption that children and adults respond to these factors in a similar manner. Although some research has focused on children, the empirical evidence linking obesity to rising 
national income, urbanization and education is best established for women.

Among women, economic development is associated with reduced food prices, particularly of unhealthful foods, and has contributed to the rise in body weight worldwide $^{(8)}$. Growing urbanization encourages greater reliance on convenient packaged foods. Urban dwellers in both more and less developed countries consume more animal-sourced foods and high-energy sweetened foods and participate less in physical activity than those living in rural areas ${ }^{(9)}$. Such work further identifies educational attainment and urban residence as important moderators of the effects of economic development ${ }^{(10)}$. In the early stages of the nutrition transition, obesity tends to be concentrated in urban areas and among people with higher socio-economic status (i.e. those with more education and income). However, as national income increases, obesity tends to increase the most among the poor and in rural areas ${ }^{(9,11-14)}$.

Yet economic development and urbanization may be only weakly related to the rise in childhood obesity. Martorell et al. ${ }^{(15)}$ examined nutritional surveys conducted during the late 1980s and 1990s across fifty less developed countries, finding a weak positive association between the prevalence of child overweight and gross national product $(r=0 \cdot 28)$. Additionally, they found that in only about half of the countries examined were children living in urban areas significantly more likely to be overweight than children in rural areas; there was no difference between urban and rural areas in most of the other countries, and children in rural areas weighed more than in urban areas in two countries (Yemen and Pakistan). A systematic review of the literature on trends in childhood obesity prevalence across forty-two countries suggested that the largest increases occurred within economically developed and urbanized countries $^{(3)}$. However, apart from Martorell et al.'s study ${ }^{(15)}$ (which used older data), we know of no recent work that systematically models the relationship between changes in national income or urbanization and changes in the prevalence of childhood obesity in less developed countries.

Like adult obesity, education is clearly an important predictor of child obesity in less developed countries. For example, Martorell et $a l^{(15)}$ found that overweight among pre-school children was more common in children of mothers with more education in Latin America, the Caribbean, the Middle East and North Africa, and in no developing countries was child overweight more common among those with poorly educated mothers. However, there exists little evidence that the association between economic development and childhood obesity is stronger for children with less educated mothers. Even among middle-income countries experiencing rapid economic development such as Iran ${ }^{(16)}$, India ${ }^{(17)}$, China ${ }^{(18)}$ and Mexico ${ }^{(19)}$, overweight and obesity remain more prevalent among children with higher educated mothers than less educated mothers. One possible exception may be Brazil, where most research finds no relationship between maternal education and child weight ${ }^{(20)}$.

In the present paper we evaluate how the socioeconomic and country-level factors associated with obesity differ between children and their mothers. We use ninety-five surveys from thirty-three less developed countries to model the likelihood of overweight for pre-school children (aged 2-4 years) and their non-pregnant mothers. By comparing children with their mothers, we ensure that the community and home environments of the children and adults in our sample are identical, thus allowing us to focus on how children and women respond differently to urbanization and economic development.

\section{Methods}

\section{Data}

Ninety-five nationally representative health and nutrition surveys conducted between 1990 and 2008 from thirtythree less developed countries were pooled for the analysis. The surveys include two countries in East Asia and the Pacific; two in Europe and Central Asia; six in Latin America and the Caribbean; three in the Middle East and North Africa; three in the South Asia subcontinent; and seventeen in Sub-Saharan Africa.

The majority of the data comes from Demographic and Health Surveys (DHS), which use standardized survey instruments across countries. The DHS are nationally representative household surveys of mothers aged 15-49 years and their children under the age of 5 years. The DHS collect information primarily on health, nutrition and family planning. To supplement the DHS, we use comparable data collected in Mexico and China. The Mexican data come from the Mexican Family Life Survey (MxFLS), which is a nationally representative survey of individuals, households and communities. The MxFLS collects social, economic, demographic and health behaviour information from all respondents. The Chinese data come from the China Health and Nutrition Survey (CHNS), a survey that covers nine geographically and sociodemographically diverse provinces in China. The focus of the survey is to collect health, nutrition and family planning data.

We were interested in assessing change in the prevalence of overweight within countries. Therefore to be included in the analytic sample a country had to have a minimum of two surveys at different points in time at least 3 years apart with the most recent survey occurring in the 2000s. If the survey was collected over two calendar years, the survey year is treated as having been conducted in the earlier year.

There are two analytic data files. The child file contains a record for each child in the ninety-five surveys, with mothers' information attached to each child record. The mother file contains a record for each mother of the children in the child file. Both are restricted to countries 
with information on child and mother's measured height and weight. Pregnant women and their children are dropped from the samples due to the confounding between BMI and pregnancy. We restrict all analysis to children (and their mothers with children) between the ages of 2 and 4 years because of the difficulties assessing overweight for younger children. Only cases with complete information on the dependent and independent variables were used in the analysis. The final analytic samples include 253442 children and 228655 mothers.

\section{Dependent variable}

All ninety-five surveys collected measured height and weight of the mother and child. The key dependent variable is a dichotomous indicator of overweight status $(=1)$ constructed separately for the children and adults. Overweight status was determined by an individual's BMI $\left(\mathrm{kg} / \mathrm{m}^{2}\right)$. For children and mothers younger than 20 years, we used the 'zanthro' program in the STATA statistical software package version $11 \cdot 0$ to convert BMI to percentile BMI based on the US Centers for Disease Control and Prevention growth charts which are standardized based on age and $\operatorname{sex}^{(21)}$. Weight assessments based on the Centers for Disease Control and Prevention and International Task Force on Obesity measures are highly correlated ${ }^{(22)}$. Children with a percentile BMI score at or above the 85th percentile were coded as overweight. For mothers aged 20 years and older, those with $\mathrm{BMI} \geq 25 \cdot 0 \mathrm{~kg} / \mathrm{m}^{2}$ were coded as overweight.

\section{Independent variables}

The independent variables included economic development, urban residence and mother's educational attainment. Economic development of the children's country of residence in the year of interview was measured as the logged real gross national income per capita (GNI), converted to constant year 2000 \$US values and adjusted for purchasing power parity. As in prior research, we use country-specific urban-rural designations from the DHS, MxFLS and CHNS. The variability in measurement of urbanicity across countries is a limitation of our data, but standard practice in cross-national research with DHS data $^{(15)}$. We harmonized indicators of mothers' education across all of the surveys and years, distinguishing among four categories: (i) no formal education (reference); (ii) attended primary school; (iii) attended secondary school; and (iv) attended post-secondary school.

Controls included gender $(1=$ male $)$, the ages of the child (in years) and mother (in years), marital status of the mother $(1=$ married $/ 0=$ otherwise $)$, the age of the youngest child in the household (in months), the year of the survey and a dummy indicator for each country.

\section{Analysis}

We first used the child and mother files to examine descriptive statistics on all variables in the analytic files.
Also, to compare trends in overweight between children and mothers, we estimated the prevalence of overweight among children and mothers from the earliest and most recent survey years for each country separately. Changes in prevalence over time were evaluated for statistical significance with $t$ tests.

We next estimated multivariate logistic regression models predicting the likelihood of overweight. We were chiefly interested in the association of economic development (GNI), maternal education and urban residence with overweight. We pooled the mother-child files ( $n$ 482 097) to assess whether associations differed significantly between children and their mothers by testing interactions between the independent variables and a 'mother indicator' $(1=$ mother record $/ 0=$ child record). When we found significant differences between children and mothers, we estimated separate models for mothers (based on the mother file) and children (based on the child file). We were also interested in whether the relationship between economic development and overweight varied by maternal education and urban residence. We tested two-way interactions between education or urban residence and economic development in the separate child and mother models. In supplementary analyses of the pooled mother-child file, we also assessed whether these two-way interaction effects differed significantly between mothers and children by testing three-way interactions among the 'mother indicator', economic development and urban residence or education.

To help interpret the multivariate results, we present the predicted percentage overweight by varying levels of GNI, maternal education and urban/rural residence for mothers and children, while setting all other variables equal to their mean values.

All models included fixed effects for country of residence (i.e. a dummy variable for each country). By estimating models with country-level fixed effects, we hold constant the non-time-changing characteristics of countries and their populations (e.g. geography and genetics) ${ }^{(23)}$. Thus the estimated coefficient for GNI (which changes over time within countries) gives the association of within-country changes in GNI with changes in overweight. In supplementary analyses, we further used the pooled mother-child sample to estimate household-level fixed-effects models:

$$
\begin{aligned}
W_{i h}= & a+B_{1}\left(M_{i b} \cdot G N I_{b}\right)+B_{2}\left(M_{i b} \cdot E_{d b}\right) \\
& +B_{3}\left(M_{i b} \cdot \operatorname{Urban}_{b}\right)+e_{b}
\end{aligned}
$$

where $W_{i h}$ is the weight status (overweight $=1$ ) of person $i$ in household $h, M_{i b}$ is a dummy variable indicating the person is a mother, $G N I_{b}, E d_{b}$ and $\operatorname{Urban}_{b}$ indicate GNI, maternal education and urban residence, and $e_{b}$ is a household-level error term. $B_{1}, B_{2}$ and $B_{3}$ provide estimates of the difference in the effects of GNI, maternal education and urban residence between mothers and their children, 
Table 1 Weighted sample descriptive statistics

\begin{tabular}{|c|c|c|c|c|}
\hline & \multicolumn{2}{|c|}{ Children } & \multicolumn{2}{|c|}{ Mothers } \\
\hline & $\%$ or Mean & SE $(B)$ & $\%$ or Mean & $\mathrm{SE}(B)$ \\
\hline Overweightt & $20 \cdot 77$ & & $28 \cdot 57$ & \\
\hline \multicolumn{5}{|l|}{ Mother's education } \\
\hline No schooling & $36 \cdot 23$ & & $36 \cdot 33$ & \\
\hline Primary & $33 \cdot 01$ & & $32 \cdot 79$ & \\
\hline Secondary & $24 \cdot 95$ & & $25 \cdot 00$ & \\
\hline Post-secondary & $5 \cdot 81$ & & $5 \cdot 88$ & \\
\hline Child is male & $50 \cdot 87$ & & & \\
\hline Age (years) $\ddagger$ & $2 \cdot 96$ & 0.00 & $29 \cdot 73$ & 0.02 \\
\hline Age of youngest child in household (months) $\ddagger$ & $38 \cdot 71$ & 0.02 & $39 \cdot 50$ & 0.03 \\
\hline Married mother & $79 \cdot 16$ & & $78 \cdot 91$ & \\
\hline Urban residence & $36 \cdot 25$ & & $36 \cdot 32$ & \\
\hline Log of gross national income $₫ \S$ & $7 \cdot 61$ & 0.00 & $7 \cdot 60$ & 0.00 \\
\hline Yearł & $2001 \cdot 37$ & 0.01 & $2001 \cdot 37$ & 0.01 \\
\hline Sample size & 253442 & & 228655 & \\
\hline
\end{tabular}

Source: Demographic and Health Surveys; Mexican Family Life Survey; China Health and Nutrition Survey.

Sample: Children aged 2-4 years and their mothers in thirty-three less developed countries between 1990 and 2008 . Countries had a minimum of two surveys at least 3 years apart with the most recent survey in the 2000s.

tChild's overweight is based on the US Centers for Disease Control and Prevention age- and sex-standardized growth charts. A percentile BMI at or above the 85 th percentile is coded as overweight. Mother's overweight is defined as $\mathrm{BMI} \geq 25 \cdot 0 \mathrm{~kg} / \mathrm{m}^{2}$. $\ddagger$ Values are presented as mean.

§Gross national income is measured per capita in constant year 2000 \$US values and adjusted for purchasing power parity. The measure is log-transformed.

net of the effects of the shared environment of mothers and their children (these models cannot estimate main effects for these variables because they do not vary within households).

Except for the household fixed-effects models, all models adjust the standard errors for the clustering of mothers and children in the same households in each particular country and year, and were estimated using the 'logit' command in STATA version 11.2. All descriptive statistics and models were weighted based on provided person-level survey weights*. We distinguished among three levels of statistical significance: $P<0 \cdot 05, P<0 \cdot 01$ and $P<0 \cdot 001$.

\section{Results}

Table 1 presents the weighted sample descriptive statistics for the child and mother samples. Mothers are more likely to be overweight than their children (28.6\% v. 20.8\%), consistent with prior empirical research. More than $36 \%$ of mothers in the sample have no formal schooling while one-third of mothers have a primary level education. Another quarter of the sample has a secondary level education and the remaining $6 \%$ have more than secondary schooling. The mean age is about 3 years for children and about 30 years for mothers. Almost $80 \%$ of the mothers are married. The majority of the sample resides in a rural location (36\% urban).

The prevalence of overweight in the earliest and most recent survey for each country is shown in Table 2

* The MxFLS and CHNS do not include survey weights; therefore, each child has a weight of 1 for these surveys. separately for children and mothers. In the earliest survey, the prevalence of overweight for children ranged from $5.3 \%$ in Bangladesh to $41 \cdot 1 \%$ in Armenia. The pattern was similar in the latest survey; Bangladesh again had the lowest prevalence at $2.5 \%$ while Egypt had the highest prevalence at $40 \cdot 1 \%$. The change in overweight prevalence for children between the two surveys was minimal for most countries; many countries experienced small declines over time (fourteen out of thirty-three). The prevalence of overweight exhibits a much wider range for mothers: from about $2 \%$ in Nepal to over $60 \%$ in Mexico and Jordan in the earliest survey. Additionally, in a majority of the sample countries mothers have a higher prevalence of overweight in both time points compared with children. Unlike children, mothers tend to experience larger gains in overweight prevalence between the earliest and latest surveys.

Having established the dissimilar patterns in overweight for mothers and children, we turn to the multivariate analysis. Using a file which pools the mother and child files together, we first assessed whether the associations of economic development, urban residence and maternal education with overweight differed significantly between children and their mothers. They did. All three interactions between these factors and a 'mother indicator' were highly significant $(P=0.000,0.000$ and 0.000 , respectively). We therefore estimated and present separate models for mothers and children.

As shown in Table 3 and depicted in Fig. 1 as predicted percentages, maternal education, urban residence and GNI were significantly and positively associated with overweight among mothers, consistent with prior research on less developed countries, but these patterns did not 
Table 2 Weighted prevalence of overweightt for earliest and latest survey by country among children and mothers

\begin{tabular}{|c|c|c|c|c|c|c|c|c|c|c|}
\hline \multirow{2}{*}{$\begin{array}{l}\text { Region/country (earliest survey date; } \\
\text { latest survey date) }\end{array}$} & \multicolumn{3}{|c|}{ Children } & \multicolumn{2}{|c|}{ Sample size } & \multicolumn{3}{|c|}{ Mothers } & \multicolumn{2}{|c|}{ Sample size } \\
\hline & Earliest & Latest & Change & Earliest & Latest & Earliest & Latest & Change & Earliest & Latest \\
\hline \multicolumn{11}{|l|}{ Latin American \& Caribbean } \\
\hline Peru $(1991 ; 2007)$ & $37 \cdot 1$ & $31 \cdot 2$ & $-5 \cdot 9^{* \star *}$ & 3807 & 5656 & $42 \cdot 1$ & $53 \cdot 4$ & $11 \cdot 3^{\star \star \star}$ & 3306 & 5252 \\
\hline Colombia $(1995 ; 2005)$ & $17 \cdot 6$ & $15 \cdot 7$ & $-2 \cdot 0^{(*)}$ & 2359 & 6490 & $41 \cdot 2$ & $40 \cdot 8$ & -0.4 & 2085 & 5947 \\
\hline Nicaragua $(1998 ; 2001)$ & $25 \cdot 0$ & $24 \cdot 0$ & $-1 \cdot 0$ & 3672 & 3109 & $40 \cdot 5$ & $48 \cdot 3$ & $7 \cdot 8^{\star \star \star}$ & 3158 & 2752 \\
\hline Mexico (2002; 2005) & $20 \cdot 4$ & $21 \cdot 1$ & $0 \cdot 7$ & 1409 & 957 & $63 \cdot 2$ & $60 \cdot 1$ & $-3 \cdot 1$ & 1267 & 875 \\
\hline Haiti (1994; 2005) & $10 \cdot 4$ & $12 \cdot 3$ & $1 \cdot 9$ & 1230 & 1167 & $11 \cdot 4$ & $22 \cdot 3$ & $10 \cdot 9^{\star \star *}$ & 1073 & 1038 \\
\hline Bolivia $(1993 ;$ 2008) & $24 \cdot 9$ & $33 \cdot 1$ & $8 \cdot 2^{\star \star \star}$ & 733 & 4040 & $39 \cdot 6$ & $55 \cdot 0$ & $15 \cdot 4^{* \star *}$ & 732 & 3639 \\
\hline \multicolumn{11}{|l|}{ South Asia } \\
\hline India (1998; 2006) & $8 \cdot 5$ & $4 \cdot 4$ & $-4 \cdot 1^{\star \star \star}$ & 5986 & 20208 & $6 \cdot 1$ & $9 \cdot 1$ & $3 \cdot 0^{\star \star \star}$ & 5966 & 18092 \\
\hline Nepal (1995; 2006) & $7 \cdot 1$ & $3 \cdot 5$ & $-3 \cdot 6^{\star \star \star}$ & 870 & 2695 & 1.9 & $7 \cdot 4$ & $5 \cdot 5^{\star \star \star}$ & 865 & 2435 \\
\hline Bangladesh (1996; 2007) & $5 \cdot 3$ & $2 \cdot 5$ & $-2 \cdot 8^{\star \star \star}$ & 2033 & 2663 & $4 \cdot 1$ & $9 \cdot 1$ & $5 \cdot 0^{\star \star \star}$ & 1905 & 2497 \\
\hline \multicolumn{11}{|l|}{ East Asia \& South-East Asia } \\
\hline Cambodia (2000; 2005) & $6 \cdot 9$ & $4 \cdot 6$ & $-2 \cdot 3^{*}$ & 1635 & 1822 & $6 \cdot 6$ & $10 \cdot 0$ & $3 \cdot 4^{\star *}$ & 1509 & 1654 \\
\hline China $(2000 ; 2006)$ & $24 \cdot 5$ & $31 \cdot 0$ & $6 \cdot 5$ & 175 & 168 & $12 \cdot 4$ & $21 \cdot 1$ & $8 \cdot 7^{\star}$ & 170 & 166 \\
\hline \multicolumn{11}{|l|}{ Sub-Saharan Africa } \\
\hline Senegal $(1993 ;$ 2005) & $10 \cdot 2$ & $5 \cdot 4$ & $-4 \cdot 8^{\star \star \star}$ & 1929 & 1162 & $18 \cdot 0$ & $22 \cdot 4$ & $4 \cdot 4^{*}$ & 1712 & 1053 \\
\hline Malawi (1992; 2004) & $34 \cdot 3$ & $30 \cdot 5$ & $-3 \cdot 8^{*}$ & 1307 & 3434 & $9 \cdot 2$ & $13 \cdot 6$ & $4 \cdot 4^{* \star \star}$ & 1195 & 3197 \\
\hline Uganda $(1995 ; 2006)$ & $23 \cdot 7$ & $21 \cdot 8$ & $-1 \cdot 9$ & 1463 & 1033 & $10 \cdot 5$ & $15 \cdot 1$ & $4 \cdot 6^{\star \star}$ & 1400 & 895 \\
\hline Tanzania $(1991 ; 2004)$ & $19 \cdot 3$ & $17 \cdot 5$ & $-1 \cdot 8$ & 2708 & 3204 & $11 \cdot 5$ & $15 \cdot 0$ & $3 \cdot 5^{\star *}$ & 2466 & 2860 \\
\hline Kenya $(1993 ; 2008)$ & $17 \cdot 2$ & $15 \cdot 5$ & $-1 \cdot 7$ & 2368 & 1139 & $13 \cdot 4$ & $23 \cdot 0$ & $9 \cdot 6^{\star \star \star}$ & 2051 & 1002 \\
\hline Namibia $(1992 ; 2007)$ & $9 \cdot 6$ & $10 \cdot 1$ & 0.5 & 999 & 1534 & $22 \cdot 3$ & $28 \cdot 5$ & $6 \cdot 2^{\star \star}$ & 905 & 1443 \\
\hline Burkina Faso (1992; 2003) & $13 \cdot 2$ & $14 \cdot 4$ & $1 \cdot 2$ & 1913 & 3490 & $7 \cdot 7$ & $7 \cdot 5$ & -0.2 & 1791 & 3297 \\
\hline Rwanda (2000; 2005) & $25 \cdot 2$ & $26 \cdot 9$ & $1 \cdot 7$ & 2629 & 1699 & $14 \cdot 7$ & $12 \cdot 6$ & $-2 \cdot 1^{(*)}$ & 2344 & 1492 \\
\hline Madagascar (1997; 2004) & $9 \cdot 0$ & $10 \cdot 9$ & $1 \cdot 9$ & 635 & 2103 & $3 \cdot 9$ & $5 \cdot 2$ & $1 \cdot 3$ & 633 & 1906 \\
\hline Mozambique (1997; 2003) & $23 \cdot 1$ & $25 \cdot 7$ & $2 \cdot 5$ & 707 & 3586 & $10 \cdot 5$ & $12 \cdot 1$ & $1 \cdot 6$ & 703 & 3305 \\
\hline Cameroon (1998; 2004) & $25 \cdot 2$ & $28 \cdot 7$ & $3 \cdot 5$ & 396 & 1350 & $21 \cdot 4$ & $26 \cdot 1$ & $4 \cdot 7^{(\star)}$ & 389 & 1201 \\
\hline Mali $(1995 ; 2006)$ & $9 \cdot 5$ & $13 \cdot 1$ & $3 \cdot 6^{\star *}$ & 880 & 4432 & $11 \cdot 1$ & $17 \cdot 0$ & $5 \cdot 9^{* \star \star}$ & 879 & 4003 \\
\hline Nigeria $(2003 ; 2008)$ & $17 \cdot 9$ & $21 \cdot 8$ & $3 \cdot 9^{\star *}$ & 1789 & 8053 & $23 \cdot 5$ & $23 \cdot 5$ & $0 \cdot 0$ & 1619 & 7238 \\
\hline Ghana (1993; 2008) & $9 \cdot 9$ & $15 \cdot 4$ & $5 \cdot 5^{\star \star}$ & 466 & 1147 & $14 \cdot 1$ & $28 \cdot 4$ & $14 \cdot 3^{\star \star \star}$ & 460 & 1045 \\
\hline Zambia $(1992 ; 2007)$ & $19 \cdot 8$ & $25 \cdot 7$ & $5 \cdot 8^{\star \star \star}$ & 1982 & 2278 & $16 \cdot 0$ & $16 \cdot 8$ & $0 \cdot 8$ & 1780 & 2059 \\
\hline Niger (1992; 2006) & $7 \cdot 5$ & $14 \cdot 0$ & $6 \cdot 6^{\star \star \star}$ & 1865 & 1508 & $8 \cdot 5$ & $14 \cdot 2$ & $5 \cdot 7^{\star \star \star}$ & 1677 & 1373 \\
\hline Benin $(1996 ; 2006)$ & $9 \cdot 6$ & $21 \cdot 6$ & $12 \cdot 1^{\star \star \star}$ & 509 & 5318 & $9 \cdot 9$ & $16 \cdot 8$ & $6 \cdot 9^{\star \star \star}$ & 502 & 4871 \\
\hline \multicolumn{11}{|c|}{ North Africa, Middle East, Eastern Europe } \\
\hline Armenia $(2000 ; 2005)$ & $41 \cdot 1$ & $29 \cdot 2$ & $-11 \cdot 9^{\star \star \star}$ & 877 & 672 & $30 \cdot 6$ & $31 \cdot 5$ & 0.9 & 757 & 601 \\
\hline Morocco (1992; 2003) & $29 \cdot 8$ & $26 \cdot 6$ & $-3 \cdot 3^{*}$ & 2236 & 2770 & $33 \cdot 1$ & $44 \cdot 2$ & $11 \cdot 1^{\star \star \star}$ & 1958 & 2554 \\
\hline Egypt (1992; 2008) & $39 \cdot 7$ & $40 \cdot 1$ & 0.4 & 3790 & 4531 & $56 \cdot 9$ & $70 \cdot 9$ & $14 \cdot 0^{\star \star \star}$ & 3247 & 4067 \\
\hline Turkey $(1993 ; 2004)$ & $19 \cdot 2$ & $29 \cdot 3$ & $10 \cdot 0^{* \star \star}$ & 1591 & 2188 & $51 \cdot 9$ & $57 \cdot 3$ & $5 \cdot 4^{\star \star}$ & 1425 & 1929 \\
\hline Jordan $(1997 ;$ 2007) & $12 \cdot 6$ & $22 \cdot 7$ & $10 \cdot 2^{* \star *}$ & 2723 & 2095 & $61 \cdot 5$ & $60 \cdot 5$ & $-1 \cdot 0$ & 2154 & 1731 \\
\hline
\end{tabular}

Source: Demographic and Health Surveys; Mexican Family Life Survey; China Health and Nutrition Survey.

Sample: Children aged 2-4 years and their mothers in thirty-three less developed countries between 1990 and 2008 . Countries had a minimum of two surveys at least 3 years apart with the most recent survey in the 2000 s.

Change in overweight prevalence was significant $\left(t\right.$ test): ( $\left.{ }^{\star}\right) P<0 \cdot 10,{ }^{*} P<0.05,{ }^{* *} P<0.01,{ }^{* * \star} P<0.001$

tChild's overweight is based on the US Centers for Disease Control and Prevention age- and sex-standardized growth charts. A percentile BMI at or above the 85th percentile is coded as overweight. Mother's overweight is defined as $\mathrm{BMI} \geq 25 \cdot 0 \mathrm{~kg} / \mathrm{m}^{2}$.

operate in the same direction for children. Maternal education was not significantly associated with the likelihood of children being overweight. Also, children living in urban areas were about $5 \%$ less likely to be overweight than rural children, while urban mothers were twice as likely to be overweight as rural mothers. Finally, a $10 \%$ increase in GNI was associated with a 9\% decline $(B=-0.89$; $\exp (-0.89 \times 0 \cdot 10)-1=-0 \cdot 09)$ in the likelihood of overweight for children, but a $6 \%$ increase $(B=0.57 ; \quad \exp (0.57 \times 0.10)-1=0.06)$ for mothers. Independent of changes in education, urban residence and GNI, the likelihood of overweight increased for both children and their mothers over time. Each additional year in time was associated with a $2 \%$ increase in the odds of being overweight among children and a $1 \%$ increase among mothers.
We next tested whether the association between economic development and overweight varied by maternal education and urban residence (models available upon request). It did. In separate mother and child models, the interactions between economic development and maternal education and between economic development and urban residence were highly significant for mothers $(P=0 \cdot 000$ and $P=0.000)$ and children $(P=0.000$ and $P=0 \cdot 000)$. Additionally, we assessed whether these two-way interaction effects differed significantly between mothers and children. Using the pooled mother-child file, we tested three-way interactions among the 'mother indicator', economic development and urban residence; and in a separate model, among the 'mother indicator', economic development and education. Both three-way interaction effects were highly significant $(P=0 \cdot 000 ; P=0 \cdot 000)$. 
Table 3 Weighted logistic regression results of child's overweight/mother's overweight

\begin{tabular}{|c|c|c|c|c|}
\hline & \multicolumn{2}{|c|}{ Childt } & \multicolumn{2}{|c|}{ Mothert } \\
\hline & OR & $95 \% \mathrm{Cl}$ & OR & $95 \% \mathrm{Cl}$ \\
\hline \multicolumn{5}{|c|}{ Mother's education (Ref. $=$ no schooling) } \\
\hline Primary & 0.99 & $0 \cdot 96,1 \cdot 02$ & $1 \cdot 77^{\star \star \star}$ & $1 \cdot 71,1 \cdot 83$ \\
\hline Secondary & $0 \cdot 94^{\star \star}$ & $0.91,0.98$ & $2 \cdot 21^{\star \star \star}$ & $2 \cdot 13,2 \cdot 30$ \\
\hline Post-secondary & $1 \cdot 05$ & $0 \cdot 99,1 \cdot 12$ & $2 \cdot 02^{\star \star \star}$ & $1 \cdot 90,2 \cdot 15$ \\
\hline Urban & $0 \cdot 95^{\star *}$ & $0.93,0.98$ & $2 \cdot 10^{\star \star \star}$ & $2 \cdot 04,2 \cdot 16$ \\
\hline Log of gross national income & $0 \cdot 41^{\star \star \star}$ & $0.33,0.51$ & $1 \cdot 77^{\star \star \star}$ & $1 \cdot 42,2 \cdot 21$ \\
\hline Married mother & $1 \cdot 08^{\star \star \star}$ & $1 \cdot 04,1 \cdot 12$ & $1 \cdot 17^{\star \star \star}$ & $1 \cdot 13,1 \cdot 21$ \\
\hline Child is male & $1 \cdot 10^{\star \star \star}$ & $1 \cdot 08,1 \cdot 13$ & $1 \cdot 01$ & $0.99,1.04$ \\
\hline Age of youngest child in household & & & $1 \cdot 003^{\star \star \star}$ & $1.002,1.005$ \\
\hline Age & $1 \cdot 01$ & $1 \cdot 00,1 \cdot 03$ & $1 \cdot 06^{\star \star \star}$ & $1 \cdot 05,1 \cdot 06$ \\
\hline Year & $1 \cdot 02^{\star \star \star}$ & $1 \cdot 02,1.03$ & $1 \cdot 01^{* *}$ & $1 \cdot 00,1 \cdot 02$ \\
\hline $\begin{array}{l}\text { Log pseudolikelihood } \\
\text { Sample size }\end{array}$ & $\begin{array}{c}-116778 \cdot 44 \\
253442\end{array}$ & & $\begin{array}{c}-115836 \cdot 69 \\
228655\end{array}$ & \\
\hline
\end{tabular}

Ref., referent category.

Source: Demographic and Health Surveys; Mexican Family Life Survey; China Health and Nutrition Survey.

Sample: Children aged 2-4 years and their mothers in thirty-three less developed countries between 1990 and 2008 . Countries had a minimum of two surveys at least 3 years apart with the most recent survey in the 2000s.

The models also include country-level fixed effects (not shown).

OR and $95 \% \mathrm{Cl}$ was significant: ${ }^{\star \star} P<0.01,{ }^{\star \star \star} P<0.001$.

tChild's overweight is based on the US Centers for Disease Control and Prevention age- and sex-standardized growth charts. A percentile BMI at or above the 85th percentile is coded as overweight. Mother's overweight is defined as $\mathrm{BMI} \geq 25 \cdot 0 \mathrm{~kg} / \mathrm{m}^{2}$.

Because children and mothers differed significantly, we used the results of the separate child and mother models to generate predicted percentages overweight (Fig. 2). Among mothers, the association between national income and the risk of overweight increased the most among those with the lowest levels of education and among those living in rural areas. Among children, however, the risk of overweight declined as national income increased regardless of maternal education or urban residence.

We conducted supplementary analyses to test the robustness of our findings. We tested multivariate models that included a control for the duration of time the child was breast-fed and duration of breast-feeding for the mother's most recent birth. We had not included these variables in the other models because not all countries collected information about breast-feeding. The coefficients, while significant, did not significantly or substantively change the results. We additionally tested models separately for the youngest (age 2 years) and oldest (age 4 years) children in the sample. The results (available upon request) were consistent regardless of the age of the child. We then estimated models separately by major world region, finding substantively similar results.

Finally, we wondered whether children and mothers differ in their responses to GNI, maternal education and urban residence because they tend to live in different types of households. For example, children may tend to live in larger, higher-fertility households than mothers. We therefore estimated household fixed-effects models to control for all unmeasured characteristics of the household and community environment shared by mothers and their children. Consistent with the other findings presented here, the household fixed-effects models showed that the associations of GNI, maternal education and urban residence were significantly stronger and more positive for mothers than their own children*.

\section{Discussion}

Developed countries face a significant obesity epidemic and recent estimates suggest that less developed countries are now also at risk. While past research has focused predominantly on women in developing countries, the present study evaluates the socio-economic and country-level factors associated with overweight and makes direct withincountry comparisons between children and their mothers. Our findings challenge the idea that the factors underlying the worldwide nutrition transition operate similarly on overweight for mothers and children. As in prior studies, we find that urban residence, education and national income are associated with higher prevalence of mothers' risk of overweight, and that the burden of overweight appears to increase with rising national incomes among the least educated women and among women living in rural areas. However, among children we find weak associations of maternal education and urban residence with overweight, and a negative association between national income and overweight regardless of maternal education or urbanicity.

These findings should be interpreted in light of the study's limitations. First, many of the countries in our sample are located in Africa, so African conditions may drive the results. We were able to replicate the findings in

\footnotetext{
* The coefficient for the interaction between the 'mother indicator' and urban residence was $0 \cdot 22(P=0 \cdot 000)$; the interaction between the 'mother indicator' and economic development was $0.16(P=0.000)$; the interaction between the 'mother indicator' and primary school was 0.07 $(P=0 \cdot 000)$, secondary school was $0 \cdot 23(P=0 \cdot 000)$ and post-secondary school was $0 \cdot 25(P=0 \cdot 01)$.
} 
(a)

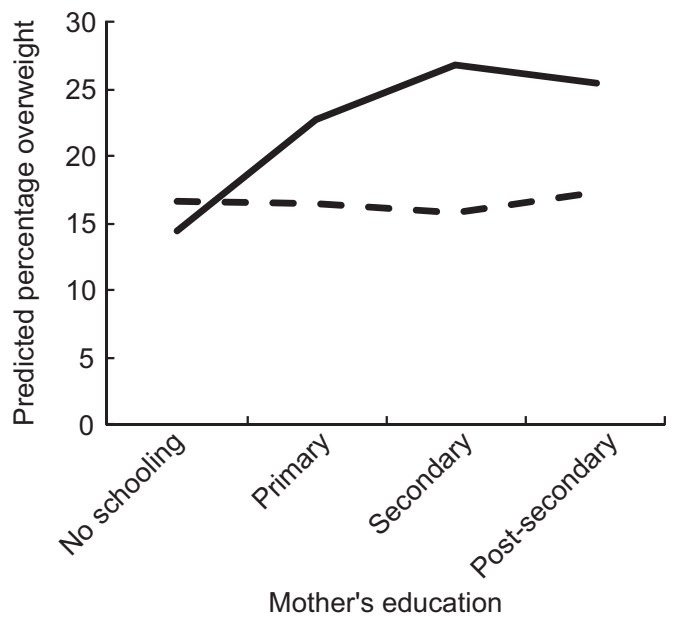

(b)

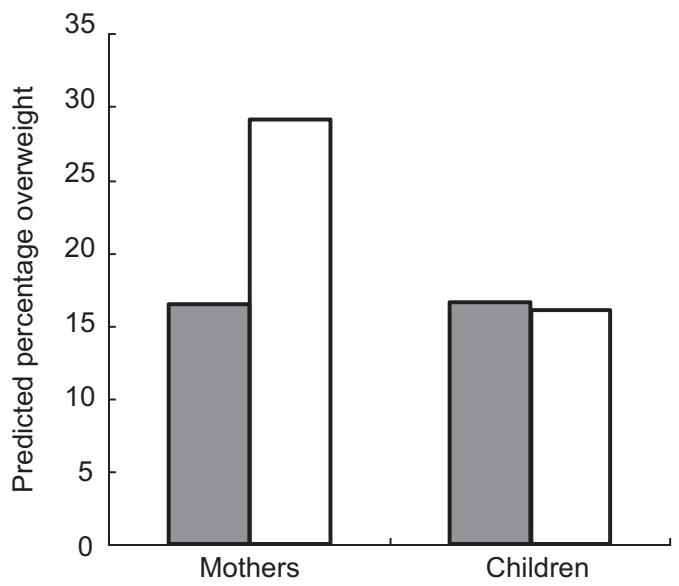

(c)

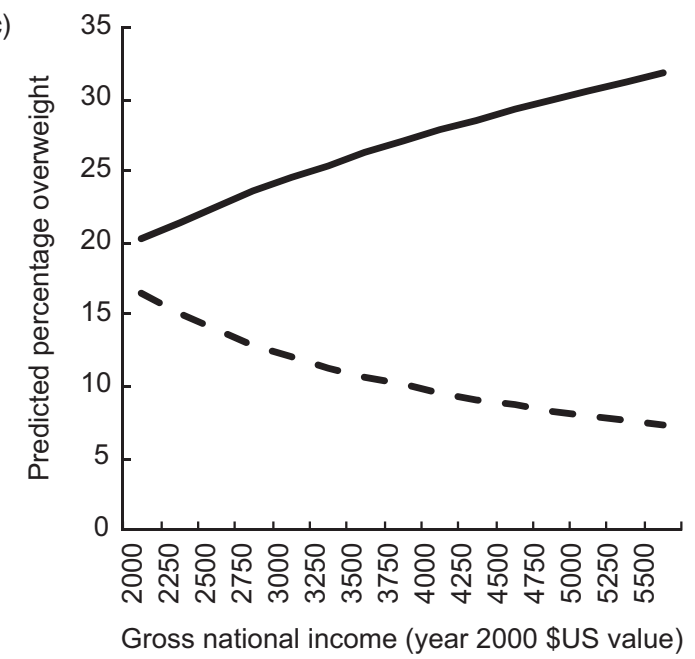

Fig. 1 Predicted obesity prevalence among children and mothers by (a) mother's education $(---$, children; - - , mothers), (b) urban residence ( $\square$, urban; $\square$, rural) and (c) national income (gross per capita and adjusted for purchasing power parity; - - - , children; - - mothers). Data analysed were from ninety-five nationally representative health and nutrition surveys conducted between 1990 and 2008 in thirty-three less developed countries, sample included children aged $2-4$ years ( $n$ 253442) and their mothers (n 228655) models estimated on each major world region, but it is important to conduct further work with a larger set of nonAfrican countries. Second, all data pertain to the 1990s and 2000s, but the specific time periods varied across countries. Recent global changes may influence children's body weight in developing countries (e.g. advances in technology, exposure to media and advertising, availability of processed food products). We were unable to examine or control for these factors. However, our analysis controlled for calendar year. Thus, the effects of GNI, education and urban residence were estimated net of time period and the associated global changes that may be affecting all countries. Third, the definition of urban residence differed across countries. More detailed and consistent measures of the level of urbanicity of mothers' and children's place of residence would be preferable. However, we included country dummies in the models, thus at least ensuring that comparisons between mothers and children are made within the same country. Even if urbanicity is defined differently across countries, we can be confident that its association with overweight differs significantly between mothers and children who share the same urban or rural environment however the concept is measured within their country.

If the results are robust, they raise the possibility that rapidly changing dietary environments in developing regions impact children differently from adults ${ }^{(24)}$. The nutrition transition model assumes that diets converge such that locally grown traditional foods are replaced by high-energy, low-nutrient foods ${ }^{(25)}$. However, there is some evidence that the shift in diets may occur differently between and within groups ${ }^{(11)}$. For example, Leatherman and Goodman ${ }^{(26)}$ examined the impact of rapid increases in national income in a less developed region, finding ample evidence of a swift nutrition transition. As local diets shifted to a higher consumption of processed energy-dense but nutrient-poor foods, adults increasingly became obese yet the children exhibited signs of growth stunting. Stunting occurs due to an absence of adequate nutrients during gestation and up to the second or third year of life $\mathrm{e}^{(27)}$, and leads to higher likelihood of obesity in adulthood. The existence of 'dual burden' households (households characterized by overnutrition among adults and undernutrition among children) in developing countries offers further evidence that children and adults may respond differently to a rapidly shifting nutritional environment ${ }^{(28,29)}$.

We further speculate that income increases at the national level may be associated with worse child nutrition. The benefits of increased income, which often accrues due to a shift from subsistence farming to wage earning among women, may be offset by reduced access to locally produced nutritious food and decreases in health-promoting activities such as breast-feeding. Indeed, research has identified a protective effect of breast-feeding against child overweight and obesity ${ }^{(30)}$, yet only $38 \%$ of children aged $0-5$ years in developing countries are exclusively breast-fed ${ }^{(31)}$. Increases in maternal labour force 

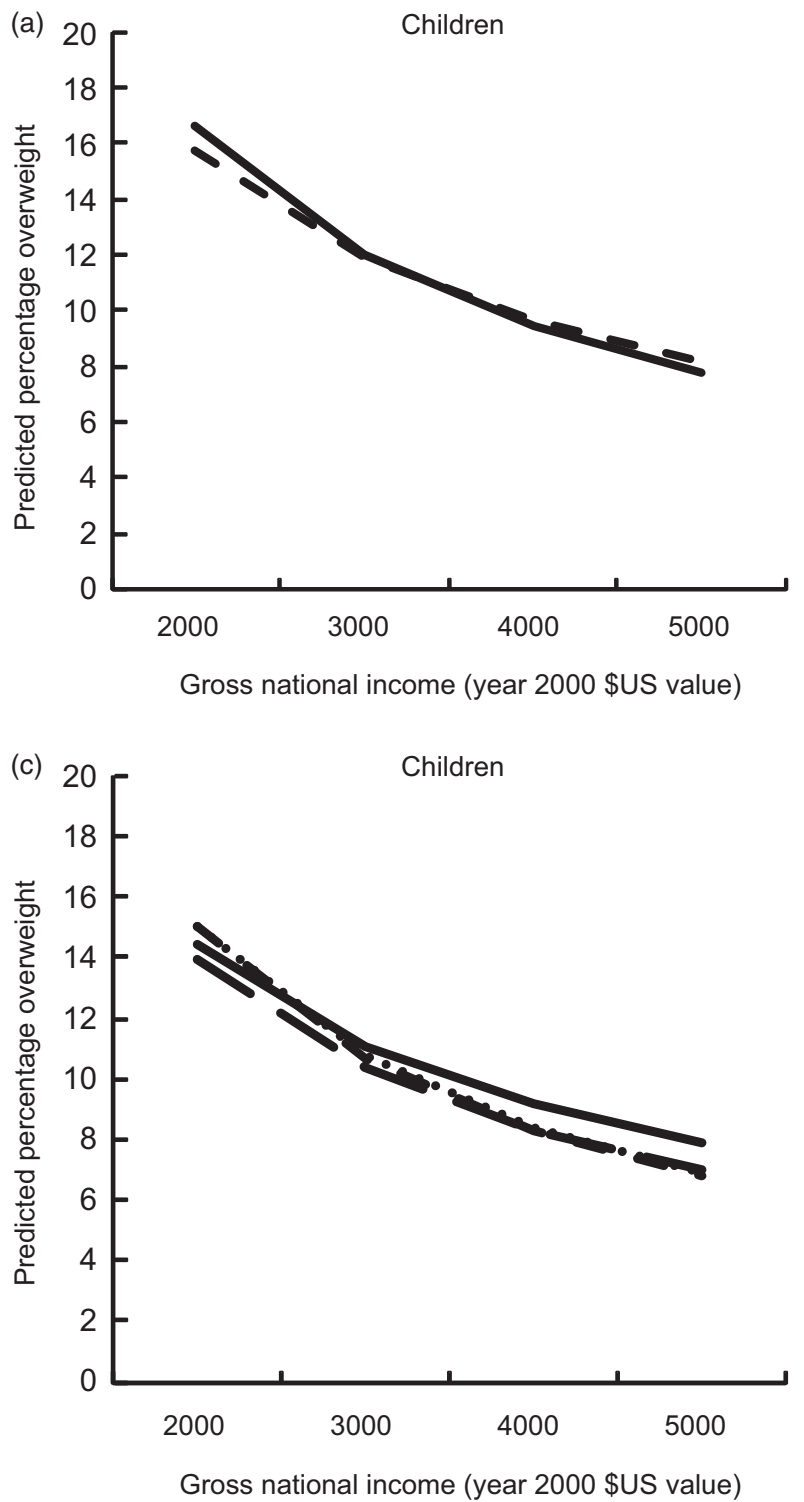
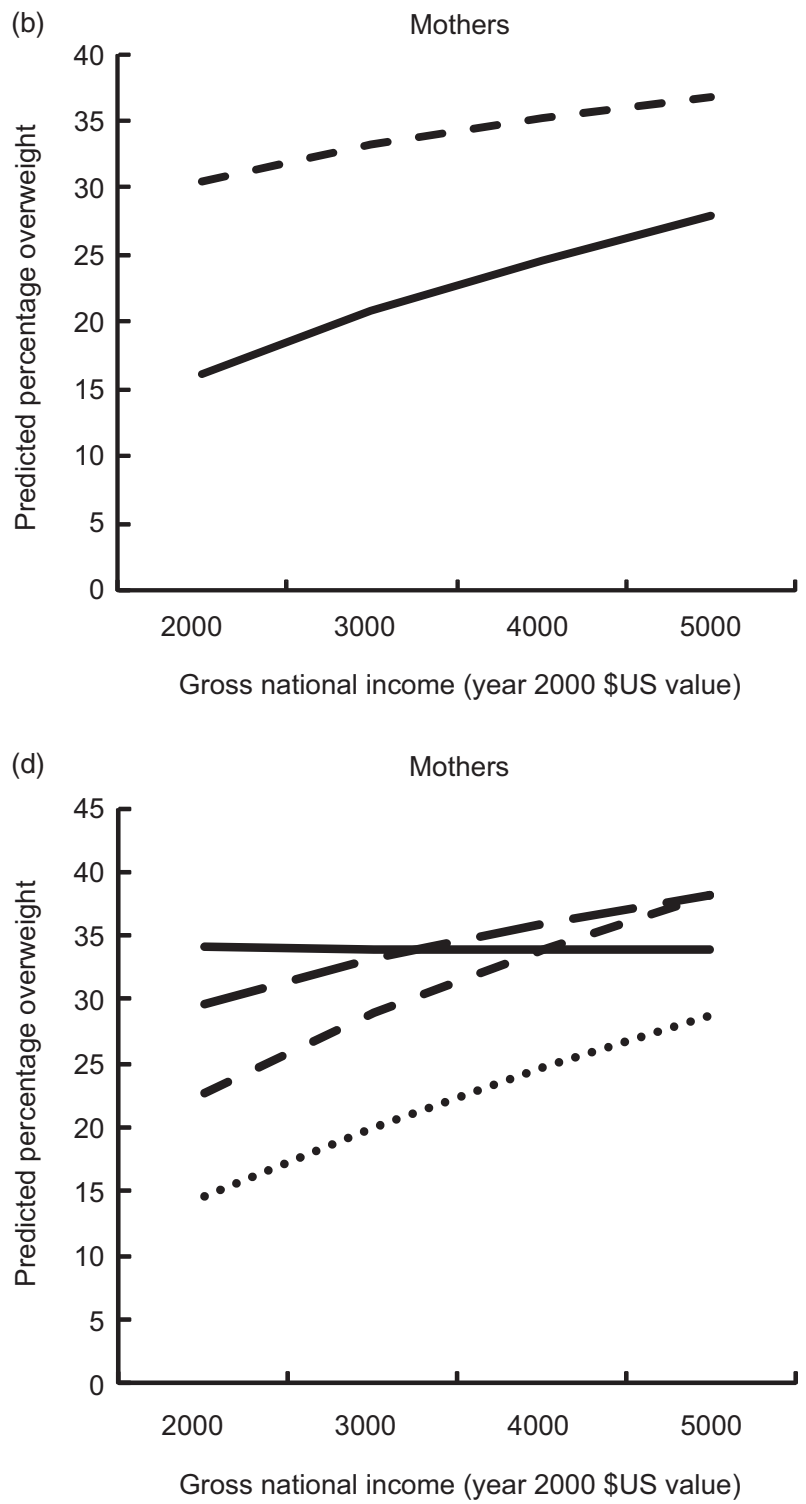

Fig. 2 Moderating effects of $(\mathrm{a}, \mathrm{b})$ urban residence $(---$, urban; — - , rural) and $(\mathrm{c}, \mathrm{d})$ mother's education (- $\longrightarrow$, post-secondary; --- , secondary; - - -, primary; $\cdots$, no schooling) on predicted obesity prevalence according to national income (gross per capita and adjusted for purchasing power parity) among children (a, c) and mothers (b, d). Data analysed were from ninety-five nationally representative health and nutrition surveys conducted between 1990 and 2008 in thirty-three less developed countries, sample included children aged 2-4 years ( $n$ 253 442) and their mothers ( $n$ 228655)

participation in developing countries are typically accompanied by reductions in breast-feeding and an increased reliance on processed foods. Although our results did not change after we controlled for the duration of breast-feeding, this underexplored factor remains a possible explanation for the distinctive patterns we observe for children, particularly for children of employed mothers.

Apart from children's diets, reductions in occupational physical activity among mothers but not children may help to explain why the prevalence of overweight among mothers (but not children) increases with increases in national income. Increases in national income are associated with reductions in physical activity due to the mechanization of labour and transportation ${ }^{(32)}$. Research from China suggests that decreases in physical activity, especially workrelated activity, are associated with increases in BMI for adults, particularly in urban areas ${ }^{(33,34)}$. Infectious disease may also help explain the findings. Uneven economic development may increase access to a continuous supply of energy-dense foods, but may also increase crowding and poor water sanitation. Children are particularly susceptible to intestinal illnesses and these illnesses make it difficult for the body to absorb nutrients from food ${ }^{(35)}$. In contexts with high levels of intestinal disease, children may be less able to gain weight than adults, even if they consume similar amounts of food. 
Finally, we note that the full impact of the nutrition transition on children in developing countries may become more apparent as children 'age into' the burden of overweight and obesity. The children in our sample are very young and the acquisition of extra body weight is cumulative. Differences in patterns of overweight by maternal education and urbanicity may emerge as children grow older and are increasingly exposed to poor nutritional environments. Data on school-aged children in developing countries is needed to more fully understand specific causes of child overweight in nutrition transition settings.

\section{Acknowledgements}

This work was supported by research grants from the National Institutes of Health (R21 HD058142) and received infrastructure support from the National Institute of Child Health \& Development provided to the Population Research Institute (2R24HD041025). The authors have no conflicts of interest. J.V.H. conceived of the idea, directed the data analysis and wrote the paper; C.E.A. constructed the data files, performed the data analysis and assisted with the literature review; K.S.B. assisted with data analysis and literature review and provided feedback at all stages. The research received (expedited) human subjects approval by the Pennsylvania State University Institutional Review Board.

\section{References}

1. Swinburn BA, Sacks G, Hall KD et al. (2011) The global obesity pandemic: shaped by global drivers and local environments. Lancet 378, 804-814.

2. World Health Organization (2011) Obesity and overweight. http://www.who.int/mediacentre/factsheets/fs311/en/ (accessed September 2011).

3. Wang Y \& Lobstein T (2006) Worldwide trends in childhood overweight and obesity. Int J Pediatr Obes 1, 11-25.

4. De Onis M, Blossner M \& Borghi E (2010) Global prevalence and trends of overweight and obesity among preschool children. Am J Clin Nutr 92, 1257-1265.

5. United Nations (2011) Prevention and Control of Noncommunicable Diseases. Report of the Secretary-General. UN General Assembly, Sixty-sixth session. New York: UN.

6. Anonymous (2011) Urgently needed: a framework convention for obesity control. Lancet 378, 741.

7. Popkin BM (2002) The nutrition transition and obesity in the developing world. J Nutr 131, 10 Suppl., S871-S873.

8. Cutler DM, Edwards EL \& Shapiro JM (2003) Why have Americans become more obese? J Econ Perspect 17, 93-118.

9. Popkin BM \& Gordon-Larsen P (2004) The nutrition transition: worldwide obesity dynamics and their determinants. Int J Obes Relat Metab Disord 28, Suppl. 3, S2-S9.

10. Monteiro CA, Moura E, Conde WL et al. (2004) Socioeconomic status and obesity in adult populations in developing countries: a review. Bull World Health Organ 82, 940-946.

11. Hawkes C (2006) Uneven dietary development: linking the policies and processes of globalization with the nutrition transition, obesity and diet-related chronic diseases. Global Health 2, 4.

12. Monteiro CA, Conde WL, Lu B et al. (2004) Obesity and inequalities in health in the developing world. Int $J$ Obes Relat Metab Disord 28, 1181-1186.
13. Popkin BM (1994) The nutrition transition in low-income countries: an emerging crisis. Nutr Rev 52, 285-298.

14. Rivera JA, Barquera S, González-Cossío T et al. (2004) Nutrition transition in Mexico and in other Latin American countries. Nutr Rev 62, 7 Pt 2, S149-S157.

15. Martorell R, Kettel Khan L, Hughes ML et al. (2000) Obesity in women from developing countries. Eur J Clin Nutr $\mathbf{5 4}$, 247-252.

16. Maddah M \& Nikooyeh B (2010) Obesity among Iranian adolescent girls: location of residence and parental obesity. J Health Popul Nutr 28, 61-66.

17. Chakraborty P \& Anderson AK (2010) Predictors of overweight in children under 5 years of age in India. Curr Res J Soc Sci 2, 138-146.

18. Dearth-Wesley T, Gordon-Larsen P, Adair LS et al. (2011) Less traditional diets in Chinese mothers and children are similarly linked to socioeconomic and cohort factors but vary with increasing child age. J Nutr 14, 1705-1711.

19. Hernandez B, Cuevas-Nasu L, Shamah-Levy T et al. (2003) Factors associated with overweight and obesity in Mexican school-age children: results from the National Nutrition Survey 1999. Salud Publica Mex 45, Suppl. 4, S551-S557.

20. Duncan S, Duncan EK, Fernandes RA et al. (2011) Modifiable risk factors for overweight and obesity in children and adolescents from Sao Paulo, Brazil. BMC Public Health 11, 585.

21. Vidmar S, Carlin J, Hesketh K et al. (2004) Standardizing anthropometric measures in children and adolescents with new functions for egen. Stata J 4, 50-55.

22. Wang Y, Wang JQ, Hesketh T et al. (2000) Standard definition of child overweight and obesity worldwide. BMJ 321, 1158-1159.

23. Allison PD (2005) Fixed Effects Regression Models for Longitudinal Data Using SAS. Cary, NC: SAS Institute.

24. Doak CM, Adair LS, Monteiro C et al. (2000) Overweight and underweight coexist within households in Brazil, China, and Russia. J Nutr 130, 2965-2971.

25. Drewnowski A \& Popkin BM (1997) The nutrition transition: new trends in the global diet. Nutr Rev 55, 31-43.

26. Leatherman TL \& Goodman A (2004) Coca-colonization of diets in the Yucatan. Soc Sci Med 61, 833-846.

27. Branca F \& Ferrarim M (2002) Impact of micronutrient deficiencies on growth: the stunting syndrome. Ann Nutr Metab 46, Suppl. 1, 8-17.

28. Garrett J \& Ruel MT (2005) The coexistence of child undernutrition and maternal overweight: prevalence, hypotheses, and programme and policy implications. Matern Child Nutr 1, 185-196.

29. Monteiro CA, Mondini L, Torres AM et al. (1997) Patterns of intra-familiar distribution of undernutrition: methods and applications for developing societies. Eur J Clin Nutr 51, 800-803.

30. Owen CG, Martin RM, Whincup PH et al. (2005) Effect of infant feeding on the risk of obesity across the life course: a quantitative review of published evidence. Pediatrics 115, $1367-1377$.

31. UNICEF (2008) The State of the World's Children 2008: Child Survival. New York: UNICEF.

32. Popkin BM (2007) Global context of obesity. In Handbook of Obesity Prevention, pp. 227-238 [S Kumanyika and R Brownson, editors]. New York: Springer.

33. Ng SW, Norton EC \& Popkin BM (2009) Why have physical activity levels declined among Chinese adults? Findings from the 1991-2006 China Health and Nutrition Survey. Soc Sci Med 68, 1305-1314.

34. Bell AC, Ge K \& Popkin BM (2001) Weight gain and its predictors in Chinese adults. Int J Obes Relat Metab Disord 25, 1079-1086.

35. Martorell R \& Yarbrough C (1980) The impact of ordinary illnesses on the dietary intakes of malnourished children. Am J Clin Nutr 33, 345-350. 